\title{
Typhoid fever in sub-Saharan Africa: Challenges of diagnosis and management of infections
}

\author{
Samuel Kariuki \\ Centre for Microbiology Research, Kenya Medical Research Institute, PO Box 43640, Nairobi, Kenya
}

\begin{abstract}
Typhoid fever, caused by Salmonella enterica serovar Typhi (S. Typhi), is a disease transmitted by the faecal-oral route. It continues to be a public health problem in many developing countries in sub-Saharan Africa. School-age children, especially those from resource-poor settings with inadequate water and sanitation systems, are disproportionately affected. It is estimated that a total of 400,000 cases occur annually in Africa, an incidence of 50 per 100,000 persons per year. Lack of effective diagnosis often leads to inappropriate treatment and management of these infections. Additionally, the emergence and spread of $S$. Typhi strains having multiple resistance to nearly all commonly available drugs in most developing countries has been a major challenge to health care systems, reducing the effective treatment options for the disease, increasing treatment costs and increasing the risk of complications and death. Although not much data from sub-Saharan Africa has been published, it seems clear that typhoid is common in Nigeria, Mali, Ethiopia and Kenya. Given the importance of information on disease incidence for targeting control measures, including improved sanitation and water supply, vaccination and assessing impact, priority should be given to strengthening surveillance systems for typhoid fever.
\end{abstract}

Key Words: Salmonella enterica serovar Typhi, typhoid fever, disease management, drug resistance

J Infect Developing Countries 2008; 2(6):443-447.

Received 27 June 2008 - Accepted 19 September 2008

Copyright (c) 2008 Kariuki. This is an open access article distributed under the Creative Commons Attribution License, which permits unrestricted use, distribution, and reproduction in any medium, provided the original work is properly cited.

\section{Introduction}

Typhoid fever, caused by the bacterium Salmonella enterica serovar Typhi ( $S$. Typhi), has become rare in industrialized countries, yet it remains a major cause of enteric disease in children in developing countries [1], resulting in an estimated incidence of 50 cases per 100,000 persons per year, predominantly in young school-age children [2]. However, this figure is a conservative estimate as few studies have been done to confirm the actual number of cases in most of Africa. In Africa the burden of typhoid fever is largely unknown mainly because credible measures of disease incidence, which inherently require confirmed diagnosis of typhoid based on blood or bone marrow culture, is almost non-existent in many endemic countries where laboratory capacity is frequently limited. So far, only a single study in Egypt [3] has reported on populationbased incidence of typhoid; the estimated incidence of typhoid fever was 59 cases per 100,000 persons per year. However, a number of hospital-based surveillance and case reports from several African countries suggests that typhoid is indeed a major public health concern, especially among school-age children. An earlier incidence study in Mali by Ferreccio et al. [4] confirmed that $S$. Typhi and $S$. Paratyphi A were major causes of bacteremia among children younger than 2 years of age, while in Nigeria cases of ileal perforation due to typhoid were common in children younger than 5 years of age [5]. A breakdown in the portable water system in a South African suburb caused an outbreak of typhoid, causing illness in nearly 4,000 persons as well as several deaths [6]. In Kenya, multidrug-resistant (MDR) S. Typhi strains in adults and school-age children were previously associated with sporadic outbreaks in resource-poor settings [7].

\section{Challenges of diagnosis of typhoid fever in Sub-Saharan Africa}

For many decades now isolation of $S$. Typhi from a blood or bone marrow culture from patients has been regarded as a definitive diagnosis for typhoid [8]. However, many laboratories in developing countries lack adequate infrastructure to perform cultures and many depend on cheaper serological tests to diagnose typhoid. In Kenya there have been reports of sporadic outbreaks of typhoid but these cases have not always been confirmed, leading to a lack of reliable data on the prevalence of typhoid in many areas reporting 
outbreaks. Some of the areas that have reported outbreaks previously were three districts in Central Kenya, Malindi and Kwale in Coast province, and parts of Nyanza province. Although no comprehensive community-based surveillance studies were conducted, our hospital-based studies (at the main referral hospital and at one private hospital in Nairobi) show that blood culture-confirmed typhoid cases occur at an incidence of 600-650 per 100,000 blood/CSF from suspected patients per year; $52 \%$ of these cases are from children younger than 10 years of age and $40 \%$ from persons aged 15 to 45 years. More than half of these cases come from the informal settlements (slum areas) near the capital city.

In a study investigating typhoid outbreaks in children in Addis Ababa, Ethiopia [9], the most frequent clinical symptoms and signs observed for suspect cases included fever, vomiting, headache, diarrhoea, abdominal pain, anorexia, cough, constipation, and convulsion. In resource-poor settings where diagnostic facilities are limited, all these symptoms could easily be found for other invasive bacterial diseases. The correct clinical impression of typhoid fever was made on $66(55.6 \%)$ of the patients. Blood culture was positive in 34 out of 54 cases with $63 \%$ positivity rate. In a previous hospital-based surveillance study at a single rural site in Kenya, we observed that with all three commercial serological kits we compared using 746 serum samples, the Widal test method would have missed out $7 \%$ of typhoid cases, while at the same time categorize another $18.7 \%$ as typhoid cases when they were not. Other studies in endemic areas of Vietnam [10] reported false negative rates of $17 \%$, which is significantly higher than for our study $(\mathrm{p}<0.01)$. For our study, only the $\mathrm{O}$ antibody titre levels were diagnostic as few samples (22\%) showed any significant rise in $\mathrm{H}$ antibody titres. In other studies performed in endemic regions of India [11], the overall sensitivity of the Widal test was $64.49 \%$ for the $\mathrm{O}$ antibody and $78.26 \%$ for the $\mathrm{H}$ antibody. Hence in the Indian study, the $\mathrm{H}$ antibody was regarded as more diagnostic, and this contrasts with our findings where $\mathrm{O}$ antibody titre levels were observed to be more predictive of typhoid. Reports from other studies also indicate that $\mathrm{O}$ antibody titres were more useful than $\mathrm{H}$ antibody titres in the diagnosis of typhoid using the Widal test method [12,13].

At a rural study site a total of 55 out of 846 serum samples tested gave significant $\mathrm{O}$ antibody titres and these were from patients from whom no bacteria were isolated from blood. This may be explained by the fact that some of the patients may have taken antibiotics prior to visiting hospital, hence making blood cultures sterile. Compared to serological methods, prior antibiotics usage creates a possible weakness in the over-reliance on blood culture as the sole diagnostic criteria for typhoid. We found out that if $\mathrm{O}$ antibody titres were high $(>1: 160)$ irrespective of culture results, a presumptive diagnosis of typhoid would still be made, and this would be confirmed by considering clinical manifestations of the patient. In addition, a clinician needs to consider other differential diagnoses that would manifest serologically with raised $\mathrm{O}$ antibody titres, including schistosomiasis, malaria, rheumatoid arthritis, nephrotic syndrome and ulcerative colitis, nontyphoidal salmonellae, and chronic liver disease $[14,15,16]$.

Using serum samples from a control population in rural Kenya, we observed that only $2 \%$ of samples showed any agglutination but none had any significant rise in titre levels of either $\mathrm{O}$ or $\mathrm{H}$ antibodies. In contrast, $50(41.6 \%)$ serum samples from controls from the Nairobi study site showed high $\mathrm{H}$ antibody titres, while $\mathrm{O}$ antibody titres (which are diagnostic for typhoid) remained low and insignificant. We attributed these findings to recent inoculation with typhoid vaccine for workers from the hospitality industry. In laboratories where titrations were not performed, or if slides were used in titration (rather than the tube method), higher titres were obtained, again leading to false positive high titre levels.

In a cross-sectional study in Ethiopia [17] conducted to determine the baseline antibody tube titration among the apparently health population, almost all the blood tested showed some titre of the antibody and reactivity of agglutination slide tests. The 95\% probability limit (mean $+2 \mathrm{SD}$ ) for anti $\mathrm{H}$ and anti $\mathrm{O}$ antigen titration was 1:276.89 and 1:207.89, respectively. These figures are closer to a cut-off titre of 1.320. There was a fair agreement between the slide agglutination test and tube titre for 0 antigen ( $p$ value $=0.225)$, and a poor agreement for $\mathrm{H}$ antigen $(\mathrm{p}$ value $=0.066$ ). These data add to the dilemma facing diagnostic laboratories in regions where typhoid is endemic.

\section{Antimicrobial resistance and challenges in management of typhoid fever}

Prior to 1992 , all $S$. Typhi isolates obtained from blood cultures of patients treated at the main referral hospital in Kenya were fully susceptible to all commonly used antibiotics. 
Resistance was first observed in 1992, at $25 \%$ to ampicillin, cotrimoxazole and chloramphenicol. Since the first report of MDR serovar Typhi outbreaks, which occurred in Kenya in 1997 to 1999 [18] when the prevalence of the MDR phenotype was 50 to $65 \%$, our current hospital-based surveillance has shown that only $13.7 \%$ isolates were fully susceptible to all drugs tested, while $75-82 \%$ of $S$. Typhi from blood cultures and CSF are MDR with particularly high MICs of ampicillin, chloramphenicol, tetracycline, (MICs > $256 \mu \mathrm{g} / \mathrm{ml}$ ), streptomycin (MIC > 1024 $\mu \mathrm{g} / \mathrm{ml}$ ) and cotrimoxazole (MIC> $32 \mu \mathrm{g} / \mathrm{ml}$ ) [7]. In all the isolates showing this multidrug resistance phenotype, a self-transferable large plasmid approximately $110 \mathrm{~kb}$ of incompatibility group HI1 was associated with encoding the resistance. In a recent hospital-based surveillance study, out of $140 \mathrm{~S}$. Typhi isolates, $15 \%$ were found resistant to nalidixic acid, $2 \%$ to ciprofloxacin and $3 \%$ to ceftriaxone. The MIC of these isolates that were resistant to ciprofloxacin ranged from 0.25 to $4 \mu \mathrm{g} / \mathrm{ml}$, showing that there was a decrease in sensitivity of $S$. Typhi to ciprofloxacin compared to the previous 5 years. The least effective drugs were cotrimoxazole and ampicillin with over $65 \%$ of isolates showing resistance (Figure 1). Mortality resulting mainly from complications associated with intestinal perforations was especially high in the very young children in an Ethiopian study [9] (Table 2), and prompt intervention including surgery and appropriate treatment was required.

Table 1. Increased MICs for quinolones for multidrugresistant $S$. Typhi from Kenya [7].

\begin{tabular}{lll}
\hline & Mode & Range \\
\hline Non-MDR* & S. Typhi & \\
Nalidixic Acid & 2 & $1-4$ \\
Ciprofloxacin & 0.016 & $0.016-0.032$ \\
MDR $S$. Typhi & & \\
Nalidixic Acid & & \\
Ciprofloxacin & 8 & $8-16$ \\
& 0.25 & $0.25-0.38$ \\
*MDR = multidrug resistant. & &
\end{tabular}

Table 2. Mortality among 108 patients with typhoid fever, by age, from an Ethiopian study [9].

Age groups $\quad$ Total Number $\quad$ Deaths $(\%)$

\begin{tabular}{ccc}
\hline$<2$ & 5 & $1(20)$ \\
5 -Feb & 10 & $4(30)$ \\
10-Jun & 40 & $7(17.5)$ \\
\hline
\end{tabular}

\begin{tabular}{ccc}
\hline 13-Oct & 43 & $5(11.6)$ \\
Total & 108 & $17(15.7)$ \\
\hline
\end{tabular}

Figure 1. Susceptibility patterns of $140 \mathrm{~S}$. Typhi isolates from outbreaks in Kenya 2004-2006 [7].

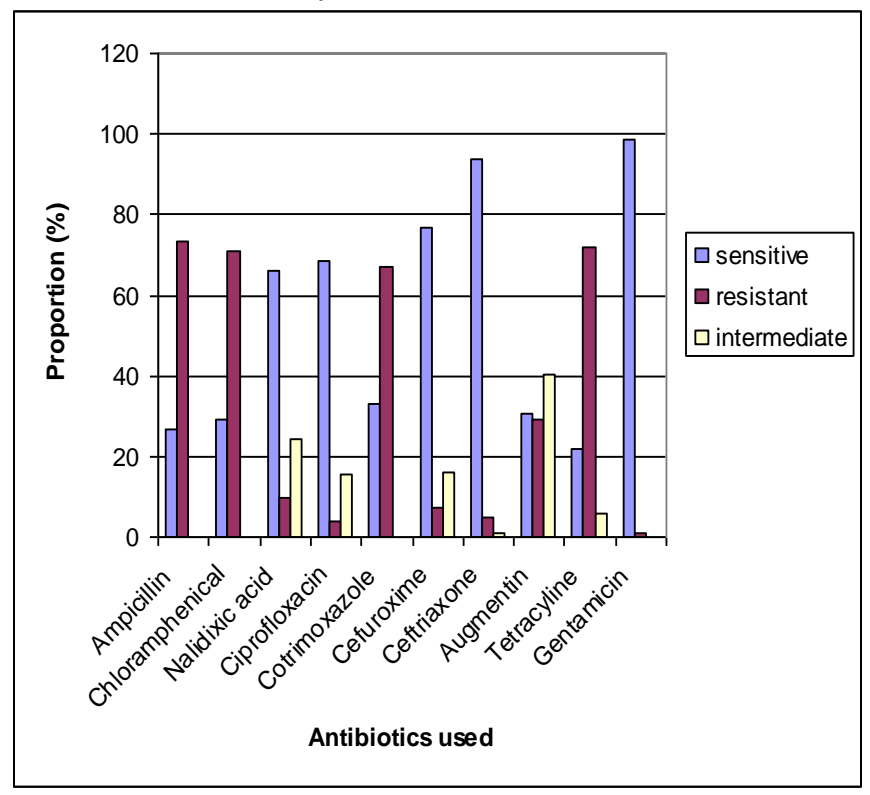

\section{Discussion}

Due to a combination of factors including poor sanitation and health care infrastructure, typhoid fever remains a major public health problem in most resource-poor countries. The Widal test is commonly used in the diagnosis of typhoid fever in Kenya as it is inexpensive and easy to perform. As a step towards accurate laboratory diagnosis, it is important that the test is performed and interpreted by laboratory personnel per the manufacturer's instructions since commercial Widal antigens in test kits are not standardized and accurately reported. Background titre levels in many developing countries are not known as studies to assess this data are very expensive because of the sample size involved and the need for isolation of the causative organism from the study subjects [19]. As some other diseases such as malaria, rheumatoid arthritis, chronic liver disease, nephrotic syndrome, and ulcerative colitis may show similar symptoms to typhoid fever and produce high $\mathrm{O}$ antibody titres, these conditions should also be evaluated as differential diagnoses in order to reduce cases of false positive Widal test results.

Previous studies and surveillance programs have shown that the prevalence of MDR $S$. Typhi has been rising steadily from $50-65 \%$ in 1997 to 1999 [18] to the present level of $70 \%$ in this study. The rise in MDR 
could be attributed to the rise in misuse of drugs that are used for treatment. Another factor could be the presence of plasmids that code for resistance in $S$. Typhi which are self-transferable; hence resistance is passed from one bacterial population to another. The antibiotics that form the mainstay of therapy in developing countries are chloramphenicol, ampicillin, and cotrimoxazole. Outbreaks of MDR $S$. Typhi - that is, resistance to all three of these first-line antibiotics - first appeared in the late 1980s in South Asia and the Middle East and then spread to Southeast Asia and Africa [20,21,22]. The emergence of multi-drug resistant $S$. Typhi strains subsequently led to the widespread use of fluoroquinolones, such as ciprofloxacin and ofloxacin, in countries where MDR is a problem. However, outbreaks of nalidixic acid-resistant typhoid with isolates showing reduced susceptibility to fluoroquinolones started to occur in Vietnam [10] and Tajikistan [23] in the early 1990s and then spread to Pakistan and India and several other countries in Southeast Asia [12,24,25,26], Kuwait [27], and Nepal [28]; often treatment of these infections with a fluoroquinolone resulted in a delay in clinical response and sometimes treatment failure. Fluoroquinolone resistance is now common in countries such as India [29] and Bangladesh [30]. The increasing rate of isolation MDR $S$. Typhi with high MICs to fluoroquinolones is increasingly a major concern in the treatment of typhoid, especially in resource-poor settings.

The emergence of MDR $S$. Typhi that are also showing resistance to quinolones in Kenya and other sub-Saharan Africa is of great concern because these antibiotics are also commonly used for treatment of other bacterial infections in hospitals, hence posing a major challenge to health care. Previously, due to the increase of MDR in many parts of the world, the drug of choice for treatment of $S$. Typhi had been ciprofloxacin. Sporadic cases of ciprofloxacin treatment failure in typhoid fever have been reported in Europe and, more recently, in Asia [31,12]. The increase of MDR $S$. Typhi has been attributed to the misuse of drugs, not only in the treatment of typhoid, but also in the treatment of other diseases that may be caused by other organisms. Over-the-counter prescription and sale of antibiotics and selfprescriptions are other factors that led to the development of the MDR organisms. The way to reduce resistance is through educating people on the proper use of antibiotics. Legislation that exists in most of these countries restricting over-the-counter dispensing of drugs without prescription also needs to be enforced.

\section{Conclusion}

As humans are the only source of infection, and transmission of $S$. Typhi is by the faecal-oral route through contaminated water or food, prevention measures need to include water and sanitation improvements, as well as health education. However, the development of an adequate infrastructure for improved water and sanitation requires large investments, and is therefore a far-off objective for the poorest countries in the world. Typhoid fever can be effectively treated with antibiotics, but growing rates of antibiotic resistance in many countries are making this treatment option increasingly more difficult and costly. Given these facts, it is necessary to consider a comprehensive approach to prevent this disease that combines the short- to medium-term measure of targeted vaccination of high-risk populations, with the longer term solutions of water and sanitation improvements and elevated living standards. The major barrier to this tactic is our inability to identify where the high-risk populations are in sub-Saharan Africa. The challenge, therefore, is to establish surveillance using new simple but effective, yet to be developed, diagnostics.

\section{References}

1. Ivanoff $\mathrm{B}$, Levine MM, Lambert $\mathrm{PH}$. Vaccination against typhoid fever: present status. Bull WHO 1994; 72: 957-791.

2. Crump JA, Luby SP, Minta ED. The global burden of typhoid fever. Bull WHO 2004; 82:346-353.

3. Srikantiah P, Girgis FY, Luby SP, Jennings G, Wasfy MO, Crump JA, Hoekstra RM, Anwer M, Mahoney FJ. Populationbased surveillance for typhoid fever in Egypt. Am J Trop Med Hug 2006; 74: 114-119.

4. Ferreccio C, Levine MM, Manterola A, Rodriguez G, Rivara I, Prenzel I, Black RE, Mancuso T, Bulas D. Benign bacteremia caused by Salmonella typhi and paratyphi in children younger than 2 years. J Pediatr. 1984; 104:899-901.

5. Uba AF, Chirdan LB, Ituen AM, Mohammed AM. Typhoid intestinal perforation in children: a continuing scourge in a developing country. Pediatr Surg Int. 2007; 23:33-9.

6. Sidley P. Typhoid outbreak prompts protests over inadequate water system. BMJ. 2005; 331:655.

7. Kariuki S, Revathi G, Muyodi J, Mwituria J, Munyalo A, Mirza A, Hart CA. Characterization of multidrug resistant typhoid outbreaks in Kenya. J Clin Microbiol 2004; 42: 1477-1482

8. Hoffman, SL, Punjabi, NH, Rockhill, RC, Sutomo, A, Rivai, AR and Pulungsih, SP. Duodenal string-capsule culture compared with bone-marrow, blood and rectal-swab cultures for diagnosing typhoid and paratyphoid fever. J Infect Dis. 1984; 149: 157-161.

9. Worku, B. Typhoid fever in an Ethiopian children's hospital: 1984-1995. Ethiop. J. Health Dev. 2000;14:311-315 
10. Parry, CM, Hoa, NTT, Diep, TS, Wain, J, Chinh, NT, Vinh, H, Hien, TT, White, NJ, Farrar, JJ. 1999. Value of a single-tube Widal test in diagnosis of Typhoid Fever in Vietnam. J. Clin Microbiol 37: 2882-2886.

11. Dutta S, Sur D, Manna B, Sen B, Deb AK, Deen JL, Wain J, Von Seidlein L, Ochiai L, Clemens JD, Kumar Bhattacharya S. Evaluation of new-generation serologic tests for the diagnosis of typhoid fever: data from a community-based surveillance in Calcutta, India. Diagn Microbiol Infect Dis. 2006; 56:359-365.

12. Parry SM, Palmer SR, Slader J, Humphrey T; South East Wales Infectious Disease Liaison Group. Risk factors for salmonella food poisoning in the domestic kitchen--a case control study. Epidemiol Infect. 2002; 129:277-85.

13. Shukla S, Patel B, Chintis DS. 100 years of Widal test and its reappraisal in an endemic area. Indian J Med Res 1997; 105: 53-57.

14. House D, Wain J, Ho VA, Diep TS, Chinh NT, Bay PV, Vinh H, Duc M, Parry CM, Dougan G, White NJ, Hien TT, Farrar JJ. Serology of typhoid fever in an area of endemicity and its relevance to diagnosis. J Clin Microbiol. 2001; 39:1002-1007.

15. Pang T and Puthucheary SD. 1983. Significance and value of the Widal test in diagnosis of typhoid fever in an endemic area. J Clin Pathol 36: 471-475.

16. Sharma, JR, Parma, IB, Sharma, SJ and Kesavan, A. 1993. False positive Widal reaction in malaria. Indian Pediatr 30: 1343-1347.

17. Mamo Y, Belachew T, Abebe W, Gebre-Selassie S, Jira C. Pattern of widal agglutination reaction in apparently healthy population of Jimma town, southwest Ethiopia. Ethiop Med J. 2007; 45:69-77.

18. Kariuki S, Gilks C, Revathi G, Hart CA. Genotypic analysis of multidrug-resistant Salmonella enterica Serovar Typhi, Kenya. Emerg. Infect. Dis. 2000; 6: 649-651.

19. World Health Organization. Typhoid vaccines: WHO position paper. Wkly Epidemiol Rec 2000; 75: 257-264

20. Coovadia YM, Gathiram V, Bhamjee A, Mlisana K, Pillay N, Garratt RM, Madlalose T, Short M. The emergence of multiantibiotic-resistant strains of Salmonella typhi in northern Natal-KwaZulu. S Afr Med J. 1992; 81:280-281.

21. Mirza SH, Beeching NJ, Hart CA.The prevalence and clinical features of multi-drug resistant Salmonella typhi infections in Baluchistan, Pakistan. Ann Trop Med Parasitol. 1995; 89:515519.

22. Mirza S, Kariuki S, Mamun KZ, Beeching NJ, Hart CA. Analysis of plasmid and chromosomal DNA of multidrugresistant Salmonella enterica serovar typhi from Asia. J Clin Microbiol. 2000; 38:1449-1452.

23. Murdoch DA, Banatvaia N, Bone A, Shoismatulloev BI, Ward LR, Threlfall EJ. Epidemic ciprofloxacin-resistant Salmonella typhi in Tajikistan. Lancet. 1998; 351:339.

24. Pokharel BM, Koirala J, Dahal RK, Mishra SK, Khadga PK, Tuladhar NR.Multidrug-resistant and extended-spectrum betalactamase (ESBL)-producing Salmonella enterica (serotypes Typhi and Paratyphi A) from blood isolates in Nepal: surveillance of resistance and a search for newer alternatives. Int J Infect Dis. 2006; 10:434-8.

25. Rahman M, Siddique AK, Shoma S, Rashid H, Salam MA, Ahmed QS, Nair GB, Breiman RF. Emergence of multidrugresistant Salmonella enterica serotype Typhi with decreased ciprofloxacin susceptibility in Bangladesh. Epidemiol Infect. 2006; 134:433-8.
26. Renuka K, Sood S, Das BK, Kapil A.High-level ciprofloxacin resistance in Salmonella enterica serotype Typhi in India. J Med Microbiol. 2005; 54:999-1000.

27. Dimitrov T, Udo EE, Albaksami O, Kilani AA, Shehab elDM.Ciprofloxacin treatment failure in a case of typhoid fever caused by Salmonella enterica serotype Paratyphi A with reduced susceptibility to ciprofloxacin. J Med Microbiol. 2007; 56:277-279.

28. Lewis H. Outbreak control team. International outbreak of Salmonella Goldcoast infection in tourists returning from Majorca, September-October 2005: final summary. Euro Surveill. 2005;10:E051208.3.

29. Joshi S, Amarnath SK.Fluoroquinolone resistance in Salmonella typhi and S. paratyphi A in Bangalore, India.Trans R Soc Trop Med Hyg. 2007; 101:308-310.

30. Ahmed HN, Niaz MP, Amin MA, Khan MH, Parhar AB. Typhoid perforation still a common problem: situation in Pakistan in comparison to other countries of low human development. J Pak Med Assoc. 2006; 56:230-232.

31. Butt T, Ahmad RN, Mahmood A, Zaidi S.Ciprofloxacin treatment failure in typhoid fever case, Pakistan. Emerg Infect Dis. 2003; 9:1621-1622.

Corresponding Author: Samuel Kariuki, Centre for Microbiology Research, Kenya Medical Research Institute, PO Box 43640, Nairobi, Kenya

Email: SKariuki@kemri.org

Conflict of interest: No conflict of interest is declared. 